\title{
Psychology Remedy for Dyslexia and Dysgraphia found, but Public Unaware
}

\section{Robert V Rose ${ }^{1^{*}}$ and Douglas R Rose ${ }^{2}$}

${ }^{1}$ Independent Education Management Professional, USA

${ }^{2}$ Department Chair, Professor of Music, Austin Peay State University, USA

\section{Introduction}

Professor of Cognitive Sciences at Brown University (previously a famous education professor at Harvard) published he most influential book, $A B C$ Foundations for Young Children, in 2013. In the preface to the book she gives published proof that most American students finishing first-grade still can't name and write all of the alphabet letters. The best predictor of reading success in rising first-graders, she writes, is the ability to rapidly name randomly presented alphabet letters, and kids who can write the fluently can also name them fluently, and almost never have reading problems [1].

In 2004 Robert Rose did an online study involving many K-1 teachers and hundreds of students, and showed that youngsters who practice handwriting until they can write all 26 letters in a minute or less (40 letters per minute or better) read spontaneously, and without any further instruction at all [2]. This study was undertaken in response to Maria Montessori's 1912 assertion that preschoolers learned to read spontaneously after they had learned to handwrite the letters "expertly", without defining that term.

And Rand Nelson, on his online blog, did another study which proves kids can name random letters at the same rate they can handwrite them. And kids who name 40 or more random letters per minute almost never have subsequent reading problems [3]. Nelson published this in Homeschool Magazine in 2012 [4]. And the Sunshine Academy of Seattle, a remedial school, has found that kids in the second-grade who practice giving answers to simple addition questions (like $6+8=$ ?) never have subsequent problems with math or science.

More recently, psychologist Rowe Kaple of Tuscon has published her astounding finding that most kids with "learning disorders" actually suffer from the hereditary "Reverse Position Sensation" syndrome, which often causes dysgraphia (previously called "clumsy child syndrome", "dyspraxia" or Coordination Deficit Disorder) unless they write with proper hand position [5].

Since ancient times, writing specialists have used a "remediation grip" of the writing instrument to force the hand into a proper palmdown position which ensures successful writing skill.

This fact has recently been published online with and article in Scientific Research titled Teaching Fluent Handwriting Remediates Many Reading-Related Learning Disabilities. This message has reached over 125,000 educators throughout the world [6].

And in 1999 The Harvard Educational Review published an article by Sophia Vernon, showing that Mexican children taught to handwrite well knew "phonemic awareness" without being taught this specifically. The authors recommend early handwriting practice rather than phonemic awareness instruction for young students [7].

In 2014 Rose published an online article with this information in Escalating Research, an English language Pakistani science journal [8].

Some years ago, Dr Anthony Grieco, dean of alumni affairs at the New York University School of Medicine and a classmate and friend of Rose, published this in the school's alumni newspaper Grapevine, too.
This was the first published information on the subject.

About five percent of the 50 million school students in America languish in Special Education classrooms, usually because of preventable reading problems.

And America has lost more young lives to street shootings than were lost among soldiers of the Vietnam war. Such perpetrators were rarely good in school, which needn't have occurred.

In September, 2014, Judy Woodruff of the Public Broadcasting's TV program News Hour ran a segment on how the Orton-Gillingham "multi-sensory" method of reading instruction will successfully remediate reading problems. "Multi-sensory" instruction includes instruction involving the senses of sight, hearing, and the haptics (or "kinesthesia" or "proprioception") of hand movement in writing. Ironically, Samuel Orton, the 1920s originator of the erroneous idea that "seeing backward" was the cause of dyslexia, also recommended handwriting practice as a "cure".

All conceivable methods of literacy instruction involve eyes, tongues and ears, so attention to hand position and motion are obviously the only real additions of this method.

People tend to think that sight is the primary sense of human beings, while olfaction is more important in lower mammals. Actually, the evolutionarily earliest, and universally most important sense, is sense of motion and position. Without it, bees couldn't dance to tell hive members the location of newly found honey bearing flowers, star fish couldn't open clams, and hunters would get lost in the woods.

This finding is of immense importance to both clinical psychologists, educators, and the public at large. The discovery has been obscured by the political values of politicians, the status of educators, and the selfish concerns of educator support from journalists.

But the truth can't be hidden forever. All people consider themselves to be psychologists with a good understanding of human nature. Montessori wrote that the best ages for children to learn to write and to read (the proper goal of literacy education) is from $31 / 2$ to $41 / 2$ years of age. We all know that little girls are a bit easier to learn than little boys are.

\section{References}

1. http://products.brookespublishing.com/ABC-Foundations-for-Young-

*Corresponding author: Rose VR, Independent Education Management Professional, USA, Tel: + 770-737-2503; E-mail: Rovarose@aol.com

Received: January 08, 2016; Accepted: January 18, 2016; Published: January 25, 2016

Citation: Rose RV, Rose DR (2016) Psychology Remedy for Dyslexia and Dysgraphia found, but Public Unaware. Clin Exp Psychol 2. doi:10.4172/2471-2701.1000115

Copyright: @ 2016 Rose RV, et al. This is an open-access article distributed under the terms of the Creative Commons Attribution License, which permits unrestricted use, distribution, and reproduction in any medium, provided the original author and source are credited. 


\section{Children-P637.aspx.}

2. http://www.peterson-handwriting.com/Publications/PDF_versions/ BobRoseFluencyStudy.pdf.

3. http://peterson-handwriting.com/Blog/.

4. Nelson RH (2014) Handwriting and reading, Is there a connection? Homeschool Magazine 18: 28-29.
5. http://adderworld.ning.com/forum/topics/abstract-university-of-az.

6. http://www.specialworld.net/2015/10/02/handwriting-fluency-linked-to-poorliteracy/.

7. http://hepg.org/her-home/issues/harvard-educational-review-volume-69issue-4/herarticle/a-neglected-variable-in-the-consideration-of-phono.

8. http://aeirc-edu.com/wp-content/uploads/2download-full-paper.pdf. 